\title{
Epidemiologic analysis of racial/ethnic disparities: A rejoinder to Frank and Exner
}

\author{
Jay S. Kaufman* \\ Department of Epidemiology, UNC School of Public Health, 2104C McGavran-Greenberg Hall, \\ Pittsboro Road, CB\#7435, Chapel Hill, NC 27599-7435, USA
}

Available online 11 January 2008

Keywords: Health disparities; Statistical inference; Causality; Etiology; Race/ethnicity

I am grateful for the detailed comments on my essay provided by Reanne Frank (2008), and Derek Exner and Jay Cohn (2008). Although Frank questions the potential benefit of my critiques, I nonetheless find her concerns and proposals to be quite persuasive. In future work, I hope to be more attentive to these recommendations, especially the suggestion to provide detailed re-analysis whenever data are available. While I would welcome the opportunity to discuss her essay in greater detail, I feel the need to use the limited space afforded to this rejoinder to address the more substantial disagreements found in the commentary by Exner and Cohn.

Exner and Cohn begin with a quotation from Roger Bacon on the primacy of experimental science for causal inference. I agree with this sentiment, and I believe it to be consistent with my critique of the post hoc analysis of the Studies of Left Ventricular Dysfunction (SOLVD) data in Exner et al.'s article "Lesser response to angiotensin-converting-enzyme inhibitor therapy in black as compared with white patients with left ventricular dysfunction" published in the New England Journal of Medicine (Exner, Dries,

\footnotetext{
* Tel.: +1 9199667435; fax: +1 9199662089.

E-mail address: jay_kaufman@unc.edu
}

Domanski, \& Cohn, 2001) and which is the subject of discussion. When one conditions effect estimates on sub-groups that are not randomly assigned, the benefits of randomization implied by Bacon are lost (Rothwell, 2005). Exner and Cohn seem to recognize this issue, since they insist that their paper was never intended to be more than "hypothesis-generating". Yet in many of their own subsequent citations of this paper, this modesty is nowhere evident. For example, in the 2004 report of the A-HeFT trial results for which Cohn is senior author (Taylor et al., 2004), the Exner et al. paper is cited twice. The first citation appears after the statement "Retrospective analyses of ... previous heart-failure trials strongly suggested that black patients have a clinically significant response to a combination of isosorbide dinitrate and hydralazine" (Taylor et al., 2004, p. 2050). This is remarkable because the Exner et al. paper did not investigate isosorbide dinitrate/hydralazine therapy at all. The second citation references the statement "Retrospective analyses according to race in... the Studies of Left Ventricular Dysfunction have shown significant differences between blacks and whites in the response to pharmacotherapy for heart failure" (Taylor et al., 2004, p. 2054). The statement is not only made without qualification regarding the level of evidence, but also without specifying the one significant endpoint (hospitalization). 
In their present commentary, Exner and Cohn (2008) insist that they did not gloss over the null finding for the primary endpoint (mortality), but their own citations to this study often refer broadly to lesser efficacy of angiotensin converting enzyme (ACE) inhibition in blacks compared to whites (e.g., Cohn, Loscalzo, \& Franciosa, 2003). This is echoed in the US Food and Drug Administration (FDA) Advisory Committee Briefing Document prepared by NitroMed, Inc. (2005) in support of the approval of $\mathrm{BiDil}^{\circledR}$ with race-specific labeling. The Exner et al. article is cited twice in this document, once (p. 13) with the unqualified statement that in the SOLVD trial, "black patients responded less favorably to ACE inhibition than nonblack patients." and once (p. 101) with the similarly broad statement that "a re-analysis of the SOLVD trial database has supported an attenuated effect of enalapril in black patients."

Exner and Cohn (2008) then go on to defend the matching strategy that was criticized in my essay. From a paper I cited in my critique by Greenland and Morgenstern, they extract a statement to support the position that efficiency could be improved under some conditions that they argue were plausibly met in their study (Greenland \& Morgenstern, 1990). This is a complete misunderstanding of the cited paper. Greenland and Morgenstern explain at the outset that they refer to decisions about study design before the data have been collected. They write:

"Although cohort matching prevents confounding by the matched variables, validity is not considered an advantage of matched designs, since in an unmatched study confounding by the covariates can be removed by analytic methods. Thus, the chief statistical advantage of matching is the potential gain in efficiency of the design, i.e., the potential gain in power or the reduction in variance produced by matching, given a fixed maximum cost for the study" (p. 151).

As Greenland and Morgenstern note, once the data have already been collected, as they were in the case of the SOLVD trial re-analyzed by Exner, Dries, et al. (2001), then conditioning on the covariates can be accomplished readily with statistical adjustment. In fact, there could be an advantage to the non-parametric control achieved by matching, since it avoids reliance on a specific model form (Ho, Imai, King, \& Stuart, 2007), but this would be consequential if there were important heterogeneity of the treatment effect by the matched covariates, a situation that Exner et al. do not consider.
Exner and Cohn next take issue with my assertion that groups with higher baseline risk will in general have more modest response to treatment on the ratio scale. I provided an explanation of this phenomenon using a counterfactual model, and they responded by citing an essay which argued that counterfactual models are not helpful. Regardless of the attractiveness of the explanatory model, however, the phenomenon itself is not disputed by Dawid (2002) or any other author that I am aware of, and has been noted widely without reference to the counterfactual explanation that I provided (e.g., Rothwell, 2005). Indeed, Exner and Cohn (2008) support the same distinction when they note that "...patients with left ventricular systolic dysfunction and a higher baseline risk derive greater benefit from therapeutic interventions, in terms of absolute benefit..."(my emphasis).

Finally, Exner and Cohn (2008) state that the 2001 article "...never attempted to identify genetic or environmental factors that might contribute to our observations." These authors published a response to letters to the editor several months after the original paper appeared, however, and the second sentence of this response states "Differences in therapeutic response probably relate, in part, to polymorphisms in drug receptors, drug-metabolizing enzymes, or other factors" (Exner, Domanski, \& Cohn, 2001, p. 767). Similar statements also appear in other articles on which Cohn is an author. For example, citing the Exner et al. article, a 2002 publication states: "Evidence suggests impaired vasoreactivity of African Americans, and studies suggest that nitric oxide (NO)-mediated vasodilation is impaired in the microvasculature of African-American patients" (Franciosa et al., 2002, p. 129).

I accept Frank's final point, which is that researchers such as Exner and Cohn are no doubt dedicated scientists who are committed to uncovering the causes of racial disparities. Her recommendation is therefore to avoid depreciatory attacks and to focus instead on the evidence conveyed in the published literature. We all seem to be in agreement that many authors have cited the Exner et al. New England Journal of Medicine paper (2001) injudiciously, attributing to that paper conclusions that the SOLVD data do not logically support. As I have noted in this rejoinder, however, some of these questionable interpretations of the paper are in fact authored by Exner and Cohn themselves. Despite Frank's pessimism concerning the potential value of this dialogue, I trust that in future work, Exner and Cohn's publications will reflect more of the cautious skepticism expressed in their commentary here. 


\section{References}

Cohn, J. N., Loscalzo, J., \& Franciosa, J. A. (2003). Nitric oxide's role in heart failure: pathophysiology and treatment. [Introduction]. Journal of Cardiac Failure, 9(5), S197-S198.

Dawid, A. P. (2002). Counterfactuals: help or hindrance? International Journal of Epidemiology, 31(2), 429-430, [discussion 35-38].

Exner, D. V., \& Cohn, J. N. (2008). Arguments prove nothing unless verified. A Commentary on Kaufman's "Epidemiologic analysis of racial/ethnic disparities: Some fundamental issues and a cautionary example". Social Science \& Medicine, 66(8), 16751677.

Exner, D. V., Domanski, M. J., \& Cohn, J. N. (2001). Race and responsiveness to drugs for heart failure. [Reply]. New England Journal of Medicine, 34(10), 767-768.

Exner, D. V., Dries, D. L., Domanski, M. J., \& Cohn, J. N. (2001). Lesser response to angiotensin converting-enzyme inhibitor therapy in black as compared with white patients with left ventricular dysfunction. New England Journal of Medicine, 344(18), 1351-1357.

Franciosa, J. A., Taylor, A. L., Cohn, J. N., Yancy, C. W., Ziesche, S., \& Olukotun, A., et al.A-HeFT Investigators (2002). AfricanAmerican Heart Failure Trial (A-HeFT): rationale, design, and methodology. Journal of Cardiac Failure, 8(3), 128-135.
Frank, R. (2008). Functional or futile?: The (in)utility of methodological critiques of genetic research on racial disparities in health A commentary on Kaufman's "Epidemiologic analysis of racial/ ethnic disparities: Some fundamental issues and a cautionary example". Social Science \& Medicine, 66(8), 1670-1674.

Greenland, S., \& Morgenstern, H. (1990). Matching and efficiency in cohort studies. American Journal of Epidemiology, 131(1), 151-159.

Ho, D., Imai, K., King, G., \& Stuart, E. (2007). Matching as nonparametric preprocessing for reducing model dependence in parametric causal inference. Political Analysis, 15(3), 199-236.

NitroMed. BiDil ${ }^{\circledR}$ Tablets, NDA 20-727: FDA Advisory Committee Briefing Document. <http://www.fda.gov/ohrms/dockets/ac/05/ briefing/2005-4145B2_02_01-NitroMed-Background.htm $>$ June 16, 2005 (Accessed 24.09.07).

Rothwell, P. M. (2005). Treating individuals 2. Subgroup analysis in randomised controlled trials: importance, indications, and interpretation. Lancet, 365(9454), 176-186.

Taylor, A. L., Ziesche, S., Yancy, C., Carson, P., D’Agostino Jr., R., \& Ferdinand, K., et al. African-American Heart Failure Trial Investigators (2004). Combination of isosorbide dinitrate and hydralazine in blacks with heart failure. New England Journal of Medicine, 351(20), 2049-2057, [Erratum (2005). New England Journal of Medicine, 352(12):1276]. 